\title{
No olho do furacão: compreendendo a transição de um Ambulatório de Saúde Mental Infanto-Juvenil para CAPSij à luz da Socioanálise
}

In the eye of the hurricane: understanding the transition from a child and adolescente mental health ambulatory to CAPSij in the light of Socioanalysis

\author{
Cláudia Capelini Picirilli; Daniele Pompei Sacardo
}

Universidade Estadual de Campinas

\section{RESUMO:}

Este artigo origina-se de Pesquisa Intervenção realizada em um município do interior paulista cujo objetivo centrou-se em analisar a transição do modelo de atendimento ambulatorial em saúde mental para o dispositivo de Centro de Atenção Psicossocial Infanto-Juvenil (CAPSij). Utilizou-se a Socioanálise enquanto referencial teórico-metodológico. As demais ferramentas de pesquisa envolveram observação participante; entrevista semiestruturada individual; questionário eletrônico e leitura de livro-ata. Os registros das intervenções socioanalíticas foram construídos em diário de pesquisa. A utilização deste referencial teórico-metodológico, bem como as ferramentas de pesquisa, possibilitaram o reconhecimento dos desafios enfrentados pelos trabalhadores no cotidiano do serviço; analisar as dinâmicas relacionais entre os trabalhadores e as instituições que os inscrevem; identificar as potências de uma equipe que busca resistir à precarização do trabalho; e apontar, para a macrogestão, estratégias que intentem contribuir com esta transição a partir dos princípios da universalidade e da integralidade no cuidado.

Palavras-chave: CAPSij; Socioanálise; Análise Institucional.

\section{ABSTRACT:}

This article originates from an Intervention Research carried out in a city in the state of São Paulo whose objective was to analyze the transition from the Mental Health Ambulatory (ASM) to the Children's and Youth Psychosocial Care Center (CAPSij) device. Socioanalysis was used as a theoretical-methodological framework. The other research tools involved participant observation; semi-structured individual interview; electronic questionnaire and reading of book-minutes. The records of socio-analytic interventions were constructed in a research diary. The use of this theoretical-methodological framework, as well as the research tools, made it possible to recognize the challenges faced by workers in the daily work; analyze the relational dynamics between workers and the institutions that enroll them; identify the strengths of a team that seeks to resist precarious work; and to present to macromanagement strategies that try to contribute to this transition based on the principles of universality and integrality in care.

Key-words: CAPSij; Socioanalysis; Institutional Analysis.

DOI: 10.12957/mnemosine.2020.57665 


\section{Introdução}

As décadas de 1960 e 1970 abrigam dois acontecimentos imprescindíveis para a construção deste artigo: a Reforma Psiquiátrica Brasileira e a criação da Análise Institucional. Derivado de dissertação de Mestrado Profissional em Saúde Coletiva ${ }^{1}$, este texto objetiva compartilhar a construção de pesquisa realizada em um Ambulatório de Saúde Mental InfantoJuvenil (ASM) em transição para Centro de Atenção Psicossocial Infanto-Juvenil (CAPSij), em um município de grande porte (aproximadamente quatrocentos mil habitantes) no interior do Estado de São Paulo.

Introduzindo, portanto, os dois acontecimentos citados, faz-se importante registrar que a Reforma Psiquiátrica Brasileira emergiu na década de 1970, através do Movimento de Trabalhadores em Saúde Mental, fortemente inspirada pela Psiquiatria Democrática, cujo protagonista principal foi Franco Basaglia, que desencadeou, na Itália, a criação de dispositivos de cuidado substitutivos ao modelo manicomial vigente em todo mundo. Estes novos dispositivos envolviam os hospitais abertos, os Centros de Atenção Psicossocial (CAPS) e as residências terapêuticas.

A partir daí iniciaram-se diversos outros movimentos e eventos para discutir a realidade brasileira, nascendo, a partir do I Encontro Nacional de Trabalhadores da Saúde Mental, o Movimento da Luta Antimanicomial. As propostas chegavam, aos poucos, ao governo. Documentos foram redigidos, apontando diretrizes para um tratamento extra-hospitalar que focasse a reintegração social e familiar dos sujeitos privados de sua liberdade. Foram realizadas duas Conferências Nacionais de Saúde Mental nessa época: uma em 1987 e outra em 1992.

Em 1989, o projeto de Lei $n^{\circ} 3657$, do Deputado Federal Paulo Delgado, começou a tramitar no Congresso (sendo aprovado, somente, em 2001). Esse projeto, embasado na Lei italiana, objetivava o fim dos manicômios e a construção progressiva dos serviços substitutivos (CAPS, residências terapêuticas, o trabalho de retorno à família, leitos de internação em hospital geral, entre outros).

Em 2001, portanto, foi aprovada a Lei $\mathrm{n}^{\mathrm{o}}$ 10.216, que oficialmente propôs a Reforma Psiquiátrica Brasileira. Menos de um ano depois, foi convocada a III Conferência Nacional de Saúde Mental (CNSM), que reiterou que as políticas de saúde devem ter como pressuposto básico a inclusão social, integrando-se a outras políticas como educação, assistência social e habitação (BRASIL, 2002). 
Progressivamente, foram criados inúmeros serviços, na medida em que os leitos psiquiátricos eram fechados.

Compondo a rede substitutiva no cuidado à saúde mental, os CAPS são formados por equipe interdisciplinar e dividem-se em três modalidades, a partir do recorte populacional: CAPS I, CAPS II e CAPS III. Dividem-se, também, a partir do público a ser atendido: crianças e adolescentes/jovens (CAPSij), adultos em grave sofrimento psíquico (CAPS) e adultos em uso de álcool e outras drogas (CAPSad).

Os CAPS compõem, ao lado dos serviços da Atenção Básica (AB), a Rede de Atenção Psicossocial (RAPS) e sua função é articular ações que ofertem a integralidade do cuidado em saúde mental.

Na Atenção Básica, os dispositivos mais potente para o cuidado em saúde mental são os Núcleos de Atenção à Saúde da Família (NASF). Os NASFs são formados por equipes multiprofissionais que atuam apoiando as equipes das Estratégias de Saúde da Família (ESF) através do Apoio Matricial (ou matriciamento). Embora vinculados ao território destas equipes, os NASFs não são unidades físicas independentes nem ofertam livre acesso, devendo ser acionados a partir da necessidade de cada equipe (BRASIL, 2011).

O apoio matricial é um arranjo desenvolvido a partir dos serviços especializados. Vamos supor que a equipe de referência de um serviço da Atenção Básica está atendendo um caso muito complexo relacionado às necessidades de saúde mental (mas poderão ser necessidades de saúde em cardiologia, nutrição, fonoaudiologia etc) e que as ações essenciais para o cuidado do usuário e/ou sua família extrapolam o nível tecnológico daquele serviço. Ao invés de simplesmente encaminhar o sujeito para outro serviço (de maior complexidade tecnológica), a equipe de referência da Atenção Básica solicita o apoio matricial para construir, de forma coletiva, as possíveis ações de intervenção e cuidado. Essas ações até podem resultar na inserção do sujeito em outro serviço (CAPS, por exemplo), mas na lógica do referenciamento e contrarreferenciamento, ou seja, os serviços se tornam corresponsáveis pelo cuidado integral do sujeito.

O apoio matricial, segundo Campos e Domitti (2007), poderá ser construído a partir de duas vertentes: através de encontros periódicos e regulares entre a equipe de referência da Atenção Básica e o apoiador matricial (profissional do serviço especializado); e em situação imprevista, ou urgente, na qual a equipe de referência aciona o apoio matricial, solicitando algum tipo de intervenção. 
Inegavelmente, muitos avanços se deram no sentido de construir uma sociedade sem manicômios, mas no que se refere ao cuidado infanto-juvenil observa-se um certo descompasso na implantação destes serviços.

Historicamente, as políticas públicas infanto-juvenis são negligenciadas em diversas partes do mundo, especialmente nos países em desenvolvimento. Segundo Schechtman (2005: 25), "as primeiras décadas do século 20 assinalaram um crescente interesse pela situação da infância no mundo, pelas questões demográficas e pela saúde das populações”. Com isso, prossegue o autor, houve aumento dos estabelecimentos psiquiátricos nos principais centros urbanos do Brasil que buscaram "legitimar-se como uma das instâncias reguladoras do espaço social, extrapolando os limites do asilo clássico, construindo um saber psiquiátrico ao que se vincula o surgimento da psiquiatria infantil”" (SCHECHTMAN, 2005: 26).

Há notícias de que, em 1903, Juliano Moreira e Fernandes Figueira construíram um pavilhão "anexo ao Hospital Psiquiátrico da Praia Vermelha, destinado às crianças portadoras de enfermidades mentais, as quais, até então, compartilhavam o mesmo espaço físico dos adultos" (RIBEIRO, 2006: 34). Em São Paulo, foi inaugurado o primeiro pavilhão infantil em 1921, por Franco da Rocha, no Hospital do Juqueri.

Segundo Couto e Delgado (2015), a construção social e política de uma nova compreensão para a infância e juventude foi marcada por dois eventos importantes da história: a Convenção Internacional sobre os Direitos da Criança, em 1989, na ONU, e a promulgação do Estatuto da Criança e do Adolescente (ECA), em 1990.

No que se refere à Política de Saúde Mental Infanto-Juvenil, um marco importante foi a III Conferência Nacional de Saúde Mental (CNSM), porque, além de priorizar o tema (o que não ocorreu nas conferências anteriores), convocou

o Estado brasileiro à tomada de responsabilidade pelo cuidado e tratamento de crianças e adolescentes com problemas mentais, afirmando a necessidade de esse cuidado ser pautado no reconhecimento delas como sujeitos psíquicos e de direitos, ser exercido em dispositivos de base comunitária, calcado na lógica do território e da operação em rede, e ter a inclusão social possível a cada um como o norte ético da ação de cuidado (COUTO; DELGADO, 2015: 22).

Contudo, de acordo com os autores, apesar do CAPSij constituir-se enquanto ação concreta do Estado no cuidado em saúde mental infanto-juvenil, ainda é incipiente o número de serviços implantados no país quando comparados aos CAPS para adultos em um mesmo período. A título de demonstração, no ano de 2013, o Brasil contava com 183 CAPSij e aproximadamente 2000 CAPS para adultos (COUTO; DELGADO, 2015). 
Ampliar a rede de CAPSi é um dos grandes desafios que se inscrevem ao poder público, mas não é o único: a falta de estratégias para a formação dos trabalhos e educação permanente; a fragilidade dos vínculos empregatícios, muitas vezes condicionados à terceirização na contratação; desconhecimento, por parte dos gestores, das atribuições de um CAPSij; ausência de supervisão clínico-institucional, na grande maioria dos serviços; atuação desarticulada entre os serviços; escassez de experiências que contemplem a existência de Fóruns locais (um potente espaço político que poderia contribuir para a ampliação destes dispositivos), baixos salários, entre tantos outros, podem ser observados por todo país, ainda de acordo com os autores.

Partindo desta realidade, a pesquisa de mestrado de que trata este artigo foi construída utilizando-se do referencial da Análise Institucional (A.I.).

Segundo L'Abbate (2002, p. 197 citado por PEZZATO; PRADO, 2013:163 ) a A.I. “[...] tem por objetivo compreender uma determinada realidade social e organizacional, a partir dos discursos e das práticas dos sujeitos”. Para Lourau (1993), a A.I. tem como princípio a autogestão, assumindo um papel político que possui dois rumos: a Socioanálise, cujo os fundadores são René Lourau e Georges Lapassade, e a Esquizoanálise, com fundamento nas teorias de Gilles Deleuze e Félix Guattari.

Lourau (1993) afirma também que a essência da Socioanálise não é, tão somente, analisar os outros, mas propor que o pesquisador se autoanalise o tempo todo, incluindo o momento em que realiza suas intervenções. Sendo assim, a Socioanálise pode ser tomada do lugar de um recurso utilizado para intervir e atuar dentro das instituições, enfatizando os processos microssociais e micropolíticos, a partir dos profissionais ou dos usuários da saúde coletiva (LOURAU, 1975 e 1993; HESS \& SAVOYE, 1988 e 1993 citados por L'ABBATE, 2004).

Os conceitos teóricos relacionados à A.I em ato, portanto, à Socioanálise, serão retomados na apresentação e discussão dos resultados.

\section{Metodologia}

O município pesquisado está localizado no interior do Estado de São Paulo e conta com aproximadamente quatrocentos mil habitantes. Participaram desta pesquisa onze pessoas, sendo: duas psicólogas, um psicólogo, duas terapeutas ocupacionais, uma enfermeira, uma técnica de enfermagem, o coordenador do serviço, um médico, uma médica e uma coordenadora municipal da Política de Saúde Mental. O projeto de pesquisa foi submetido ao Comitê de Ética 
e Pesquisa (CEP) da Unicamp no dia 01/09/2016 e foi aprovado no dia 28/09/2016 (n ${ }^{\circ}$ 1.750.268). Após sua aprovação, o projeto foi submetido à análise do Secretário Municipal de Saúde.

A aproximação com o campo de pesquisa se deu por meio da coordenadora municipal da Política de Saúde Mental que, através de encontros presenciais e contatos telefônicos, explicou à pesquisadora a construção da rede psicossocial municipal e o momento particular de transição do modelo de cuidado infanto-juvenil.

Posteriormente, apresentou-se o projeto de pesquisa ao coordenador do serviço e agendou-se o primeiro encontro com os trabalhadores no espaço da reunião técnica (também chamada de reunião de equipe). Neste encontro, além da apresentação dos aspectos metodológicos da pesquisa e da entrega do Termo de Consentimento Livre e Esclarecido (TCLE), começou-se a construir o que viria a ser a intervenção socioanalítica, como será melhor apresentado na seção relativa à análise da demanda.

Deste modo, utilizou-se a Socioanálise enquanto referencial teórico-metodológico. As demais ferramentas de pesquisa envolveram: observação participante; entrevista semiestruturada individual; questionário eletrônico e leitura de livro-ata.

A observação participante se deu no espaço de supervisão clínico-institucional, a convite dos trabalhadores. As supervisões ocorriam semanalmente e eram conduzidas por profissional contratada pela Secretaria Municipal de Saúde. O coordenador do serviço, assim como os médicos, não participavam destes encontros. As ausências dos médicos, tanto em relação aos encontros de supervisão clínico-institucional como em relação às reuniões técnicas (sinalizado abaixo), eram justificadas pela carga horária de trabalho reduzida (aproximadamente 12 horas semanais). O coordenador do serviço não participava das supervisões clínico-institucionais, pois realizava curso de especialização no mesmo horário. Segundo ele, foi sugerida a participação da supervisora nas reuniões técnicas, mas não foi possível por incompatibilidade de agenda da profissional.

Foram realizadas três entrevistas semiestruturadas individuais, sendo duas com a coordenadora municipal da Política de Saúde Mental e uma com o coordenador do serviço. Utilizou-se esta ferramenta com o objetivo de compreender melhor as dinâmicas institucionais.

A aplicação do questionário eletrônico se deu pela impossibilidade de contato com os profissionais médicos ao longo do percurso da pesquisa. Como havia grande demanda de trabalho, por conta dos atendimentos sequenciais que aconteciam de forma ambulatorial, não 
foi possível agendar entrevistas individuais. Do mesmo modo, como não participavam dos espaços coletivos para discussões técnicas, ausência justificada pela carga horária reduzida, o encontro entre pesquisadora e médicos se tornava cada vez mais difícil. Portanto, diante da impossibilidade de contato, a pesquisadora elaborou um questionário eletrônico, através da ferramenta Google Formulários, com perguntas fechadas, e o enviou aos profissionais através do e-mail institucional. Porém, conforme sugestão do coordenador do serviço, posteriormente, os questionários foram impressos e entregues diretamente aos médicos, através do coordenador, que também os recebeu de volta após preenchidos e os entregou à pesquisadora.

As leituras do livro-ata ocorriam anteriormente ao início das reuniões técnicas.

Por fim, as intervenções socioanalíticas ocorreram no espaço das reuniões técnicas, sendo realizados sete encontros em que estavam presentes os trabalhadores, com exceção dos dois médicos. Os registros destas intervenções foram produzidos em diário de pesquisa.

As restituições ocorriam ao longo das intervenções, momento em que a pesquisadora compartilhava com os trabalhadores suas reflexões, dúvidas e experiências, possibilitando a análise coletiva sobre o momento de transição vivenciado no serviço. O sétimo encontro foi dedicado exclusivamente à restituição e, diferentemente dos anteriores, foi registrado em gravação de áudio, com a autorização dos participantes. Tal qual os encontros anteriores, foram compartilhadas as vivências da pesquisa, as angústias relacionadas à transição do modelo de atendimento, as expectativas dos trabalhadores sobre a nova configuração do serviço e os desafios da Política de Saúde Mental daquele município. Este material será analisado e discutido a seguir.

Importante registrar também que, após sua publicação, a dissertação foi compartilhada com todos os participantes da pesquisa e, após dois anos de sua realização, uma das profissionais do serviço entrou em contato com a pesquisadora e sinalizou o quanto o material produzido ainda estaria presente em suas reflexões cotidianas.

\section{Resultados e discussão}

Os resultados a seguir foram produzidos a partir do referencial teórico da Análise Institucional (A.I.), uma vez que a inserção em campo se efetuou através da PesquisaIntervenção e contemplou as etapas que compõem a Socioanálise, a saber: análise da encomenda e da demanda; analisadores; análise da oferta e análise de implicação dos sujeitos pesquisados e da pesquisadora. Para que o material fosse construído, a pesquisadora 
compartilhava com o coletivo de trabalhadores suas impressões, dúvidas, reflexões e experiências. Deste modo, as restituições ocorreram durante as intervenções socioanalíticas e, como descrito anteriormente, no último dia da pesquisadora em campo. Com isto foi possível construir, a partir da relação com o coletivo, os pontos apresentados a seguir.

Importante assinalar que as demandas geram a encomenda, portanto, a análise da encomenda está implícita na análise da demanda. Igualmente a análise da oferta contemplou a análise de implicação da pesquisadora.

Antes de mergulharmos nos resultados, porém, é preciso registrar um fato importante para a compreensão desta pesquisa: embora ainda não cadastrados como CAPSij, a equipe pesquisada era incentivada a atuar como tal, indicando a primeira e significativa contradição decorrente dos representantes da macrogestão e, também, dos próprios trabalhadores, muitas vezes atravessados pelo desejo de construção de um modelo de cuidado que superasse a lógica do ambulatório.

Porém, ao mesmo tempo em que estavam engajados em construir um cuidado integral aos usuários do serviço (seguindo o modelo dos CAPSij), o fato de operarem enquanto serviço ambulatorial produzia importante sofrimento. Para entender este paradoxo é importante explicar que o CAPSij constitui-se como "referência para uma população de cerca de 200.000 habitantes, ou outro parâmetro populacional a ser definido pelo gestor local, atendendo a critérios epidemiológicos" (BRASIL, 2002b, Art. $4^{\circ}$ ). Isto posto, observemos o quadro abaixo:

Quadro 1 - Equipe do ASM pesquisado e equipe de CAPSij prevista legalmente:

\begin{tabular}{ll}
\hline Equipe ASM Infanto-Juvenil & Equipe prevista para CAPSi \\
1 Coordenador & 4 profissionais de nível superior entre as \\
& seguintes categorias profissionais: psicólogo, \\
& assistente social, enfermeiro, terapeuta \\
& ocupacional, fonoaudiólogo, pedagogo ou \\
3 Terapeutas Ocupacionais & outro profissional necessário ao projeto \\
& terapêutico; \\
& 1 Enfermeiro; \\
1 Enfermeira & 5 profissionais de nível médio: técnico e/ou \\
1 Técnica de Enfermagem & auxiliar de enfermagem, técnico \\
1 Recepcionista & administrativo, técnico educacional e artesão; \\
\hline 2 Médicos & \begin{tabular}{l} 
pediatra com formação em saúde mental. \\
\hline
\end{tabular}
\end{tabular}

Fonte: Elaboração própria 
Quando comparamos a coluna que trata do quadro de profissionais do ASM infantojuvenil do município pesquisado (à esquerda) e a coluna dos recursos humanos instituídos pela Portaria $n^{\circ} 336 / 2002$ (à direita), podemos incorrer no erro de afirmar que a equipe pesquisada possui um profissional de ensino superior e um médico além do previsto e, em contrapartida, faltariam três profissionais de nível técnico ou médio. Contudo, é elementar que recordemos que o recorte populacional desta legislação é de 200.000 habitantes, conforme sinalizado anteriormente, e que o Ambulatório de Saúde Mental Infanto-Juvenil, neste caso, configura-se como referência para todo o seu município, com aproximadamente 400.000 habitantes, e mais as cidades vizinhas que não contam com esta modalidade de atendimento.

Logo, com estes dados, podemos considerar que a equipe do ASM trabalha com a ausência de doze profissionais, sendo oito de ensino médio, um profissional de enfermagem e três profissionais de ensino superior, uma vez que, no contexto apresentado, observamos que o serviço recebe demandas suficientes para duas equipes de CAPSij. Soma-se a esta primeira contradição o fato de que a atual carga horária médica é extremamente diminuta.

Concluído este registro, iniciaremos as análises decorrentes da pesquisa. Os discursos e observações, extraídos do diário de pesquisa, serão representados da seguinte forma: FP (fala do profissional) e OP (observação da pesquisadora).

Algumas considerações importantes: as análises a seguir serão apresentadas em primeira pessoa, por conta da implicação (sendo a pesquisadora parte da pesquisa); os discursos dos profissionais não incluem recorte de gênero ou de núcleo profissional, por duas razões principais: 1) para que os mesmos não se sintam expostos diante da macrogestão; 2) por se compreender que as narrativas foram trabalhadas coletivamente e, portanto, não se referem tão somente àquele porta-voz, estando relacionadas aos aspectos institucionais mais profundos.

\section{Análise da encomenda e da demanda}

Segundo Lourau (1993, p. 31), “a encomenda tem origem em demandas (...) individuais e dos grupos que compõem o grande grupo da intervenção em processo". De modo resumido envolvem analisar "quem me chamou e por quê?" (encomenda) e "o que desejam aqueles que não me pediram para vir? Quais são as suas relações com aqueles que me chamaram? Etc" (LOURAU, 2004:125-6), ou seja, "todo o antes, o exterior e o depois da intervenção estão no campo de análise, incomparavelmente mais vasto que o campo de intervenção, limitado a um estabelecimento, a uma associaçãoe etc" (LOURAU, 2004: 131). 
Como descrito anteriormente, minha entrada em campo ocorreu após algumas conversas com a coordenadora municipal e após o contato com o coordenador do serviço. No momento do primeiro encontro, a proposta projetada para esta pesquisa era a observação participante. Contudo, no terceiro dia em que estive com a equipe, a encomenda para a Pesquisa-Intervenção foi verbalizada e demandou revisão metodológica: “o que você faria?” (Diário de pesquisa FP), perguntou-me um dos trabalhadores no auge da discussão de um caso clínico.

A pergunta não estava direcionada à pesquisadora, mas à trabalhadora de CAPSi que eu havia sido. Neste momento, a análise de minhas (sobre)implicações era ainda mais imprescindível. O reconhecimento do lugar de saber prático me conectou a essas pessoas, ao mesmo tempo em que mobilizou afetos em diversas direções.

Segundo fui informada, em contato telefônico, possivelmente minha entrada em campo não seria um problema, ainda mais por eu ter sido trabalhadora da saúde mental infanto-juvenil o que, segundo ele, facilitaria minha aproximação com a equipe e poderia contribuir com o momento de reorganização do serviço (Diário de pesquisa - $\mathrm{OP}$ ).

Analisando em restrospectiva, a encomenda de construção coletiva (intervenção socioanalítica) havia sido sinalizada antes mesmo de minha entrada em campo, mas naquele momento eu não soube decodifica-la. Foi preciso encontrar-me presencialmente (corporalmente) com o coletivo de trabalhadores para entendê-la.

Lembro-me das palavras de Spinoza (1632-1677/2015: 153) quando afirma que a nossa potência de agir pode ser aumentada ou diminuída a partir do encontro dos corpos e dos afetos produzidos nestes encontros. Entendo que a equipe estava em movimento e provocou movimento em mim, demandando a revisão metodológica. Havia potência de agir e esta potência também pode ser representada na seguinte fala:

eu acho que é uma equipe que trabalha, que não tem medo de arregaçar a manga, uma equipe humana, que compra a causa, bastante dedicada, é uma equipe que tem bastante conhecimento, de diversas coisas não só dos assuntos de lei, a equipe segura bem a onda... sempre tem um desafio de trabalhar com o diferente, uma pessoa não é igual à outra, não pensa como a outra. E se a coisa apertar é uma equipe que se cuida, é companheira. É uma equipe que está em processo, eu também (Diário de pesquisa - FP).

Contudo, esta encomenda revela que ao mesmo tempo em que sou acolhida pela equipe, também sou colocada no lugar de quem poderá contribuir para minimizar a angústia dos trabalhadores: "você é a luz no fim do túnel" (Diário de pesquisa - FP).

Compreendo que na fantasia inconsciente deste coletivo ocupava dois lugares que se intercalaram ao longo da pesquisa: o de salvadora e o de sobrevivente, ou seja, alguém que já 
vivenciou experiências de angústia em um equipamento semelhante e que poderá compartilhar suas histórias. Parecia-me que a equipe precisava reconhecer-se no olhar do outro, precisava encontrar no outro um lugar de acolhida e amparo neste momento de (des)organização, e compartilhei com eles esta impressão em alguns momentos.

Contudo, como a Análise Institucional busca compreender as contradições inerentes às instituições e os lugares que ocupamos, os momentos de 'salvadora do caos' também se intercalavam com a dúvida sobre quem eu era e o que eu pretendia: "você parece uma escrivã de polícia (...) parece que estou ao lado de um advogado” (Diário de pesquisa - FP). Quando esta fala apareceu, logo nos primeiros encontros, acolhi e busquei desconstruir este lugar de quem julga, analisa, defende ou acusa, resgatando meu posicionamento de sujeito-parceiro na construção desta vivência.

Ainda sobre a demanda de intervenção: em um primeiro momento este ponto poderia indicar aspectos relacionados à ausência de conhecimento operacional sobre o fazer no CAPSij; porém tanto os trabalhadores quanto a coordenadora de Saúde Mental demonstraram conhecimentos sobre o funcionamento deste dispositivo.

É possível, então, supor que a demanda estaria calcada no fato desta equipe não ter respostas concretas sobre o caminho a seguir, produzindo nebulosidade e insegurança, pois as decisões políticas não eram transmitidas de forma objetiva, conforme podemos observar nesta fala:

da sua chegada aqui também, sabe, até da supervisão, para mim, me leva à reflexão da falta de uma gestão que direcione, não que diga como fazer, mas eu acho que a gente ao mesmo tempo que tem uma autonomia para construir o serviço, tem um limite essa autonomia, tem uma hora que a gestão tem que entrar... então eu acho que, ainda aqui, o que não mudou de dezembro para cá, por mais que a gente tenha um apoio da gestora direta, mas acho que falta uma gestão maior ainda assumir algumas coisas, para justamente criar identidade desse serviço que está em processo de se tornar um serviço que atende casos de transtornos graves e severos (Diário de Pesquisa - FP).

As contradições de uma atuação no modelo de CAPSij (sem constituir-se como tal) estão centradas, como descrito anteriormente, na ausência de pelo menos doze trabalhadores, diante de importante demanda de saúde mental infanto-juvenil do município. Mas, além disso, outros pontos devem ser revelados sobre esta transição: a) a escassez de espaço físico, uma vez que o estabelecimento localiza-se em bairro residencial, em um imóvel alugado pela prefeitura e que não possui espaço suficiente para o desenvolvimento de atividades (quer seja pela quantidade de salas de atendimento, quer seja pelo espaço físico externo para realizar atividades inerentes 
à permanência-dia); b) a ausência de Política de Saúde Mental na Atenção Básica, já que o município não implantou o Núcleo de Apoio à Saúde da Família ou qualquer outra estratégia de cuidado em saúde mental na Atenção Básica, sendo deslocada para o ASM toda a demanda infanto-juvenil do município e das cidades do entorno, sejam estas demandas mais, ou menos complexas.

Esta precarização provocava dúvidas em relação às possibilidades de cuidado da equipe e, também, em relação ao limite corporal de todos (corpo dos trabalhadores, corpo do estabelecimento de saúde e corpo das instituições).

Este é um ponto fundamental que deve ser revisto pela macrogestão do município pesquisado, pois, mesmo se existissem duas equipes de CAPSij para atender toda demanda populacional, o espaço físico não seria capaz de acolhê-los. Isto foi apontado no percurso da pesquisa; contudo, o estabelecimento continua funcionando no mesmo lugar.

Poderíamos, então, sugerir que a partir da restrição de espaço parcerias fossem construídas extramuros. Porém, para que seja possível o deslocamento para outros cenários territoriais, é preciso estrutura de transporte (seja em forma de bilhete público, ou de carro exclusivo do serviço) e de trabalhadores. Com o número reduzido de profissionais, esta logística é bastante comprometida.

Podemos, então, pensar que uma forma concreta de investimento da Secretaria Municipal de Saúde neste momento de reordenamento do serviço tenha sido a contratação da supervisão clínico-institucional. Este é um dispositivo previsto pela Portaria MS/GM no 1.174/2005, desenvolvido por um agente externo juntamente à equipe do serviço, através da problematização de casos clínicos, sendo esta discussão conectada à rede, ao serviço e à gestão, estabelecendo uma relação entre as dimensões político e clínica (SEVERO; L'ABBATE; CAMPOS, 2014).

Fui convidada a participar destas supervisões e, após a assinatura do Termo de Compromisso Livre e Esclarecido (TCLE) por parte da supervisora, estive neste espaço em três momentos.

Contudo, este espaço político-institucional, que poderia se configurar como potência de construção, acabou sendo interpretado pelos trabalhadores como mais um espaço de angústia: "a supervisão só traz leis e diretrizes" (Diário de pesquisa - FP).

Nos dias de supervisão, a dinâmica do serviço mudava. Primeiro, o gestor local não estava presente, pois estava concluindo uma especialização; e, segundo, havia muitas queixas 
sobre esta atividade - queixas que não tinham uma conexão direta com a pessoa da supervisora, mas que diziam de uma angústia que se acentuava pela ampliação do vazio. Nas supervisões, de acordo com os trabalhadores, os temas não eram problematizados de forma objetiva, mas ao mesmo tempo os trabalhadores também não apontavam para a supervisora seus descontentamentos e incômodos. Era um momento de despotencialização, de falta de investimento libidinal, que os impedia de sinalizar seus afetos.

Minha sensação era a de estar diante de um corpo institucional psicótico. Tal sensação se fez palavra na voz de uma trabalhadora: "eu sinto que a equipe está compartimentalizada, falta um corpo, falta estrutura, falta sala de brinquedos, falta espaço de acolhimento adequado" (Diário de pesquisa -FP).

No momento em que esta fala se revela, eu compartilho a minha sensação e acrescento que esta "psicose institucional" demandava, no primeiro momento de crise, ser tratada de forma concreta, compreendendo que aqueles trabalhadores compunham um corpo (institucional) que, naquele momento, não conseguia simbolizar. E, na impossibilidade de simbolização, a tarefa de encontrar saídas ou projetar novas perspectivas tornava-se demasiadamente difícil porque o que se via e o que se sentia era o vazio promovido pela desorganização estrutural.

Esta ausência de posicionamento da maioria dos trabalhadores ocorria tanto nas supervisões como nos espaços de reunião de equipe técnica. Percebia-se interação entre eles em espaços informais, como na cozinha ou na hora do almoço, com os pares com quem estabeleciam vínculo de confiança, mas, no contexto coletivo, muitos se calavam enquanto outros assumiam posições de porta-vozes do grupo: um assumia o lugar de quem sempre reclamava, o outro de quem se sentia persecutório por não ter controle sobre tantas mudanças, outro representava a vida institucional tentando propor novas ações de cuidado.

\footnotetext{
"Em seguida um deles comenta, apontando para o livro-ata que eu estava em mãos: 'viu, era isso que tinha que ser feito, para entender o serviço e conhecer a história"” (Diário de pesquisa-FP).
}

Analiso que neste momento eles se conectam comigo porque interpretam o meu ato de ler a história do serviço como um cuidado. Era uma equipe que precisava de holding (utilizando o termo do psicanalista Winnicott), no sentido de acolhimento, de sustentação. O tema do holding institucional ainda não tem sido consideravelmente explorado nas produções científicas. Muito se discute sobre a alienação no trabalho, sobre os processos de adoecimento 
do trabalhador ou sobre a necessidade de educação permanente, mas é ínfima a reflexão sobre a importância do acolhimento dos trabalhadores no sentido de uma sustentação (um "colo" simbólico) institucional.

Do meu ponto de vista, este conceito não diz somente da importância da instrumentalização ou aperfeiçoamento do trabalhador para atuar em seus desafios cotidianos, mas, sim, de acolhimento da demanda de angústia, da sensação de desamparo e de aniquilamento que envolve sujeitos individuais e coletivos, principalmente em momentos de significativas transformações.

Contudo, reforço que este conceito (holding institucional) não tem sido explorado nas produções acadêmicas. Em busca de trabalhos que pudessem aprofundá-lo, encontrei o artigo de Golin e Benetti (2013: 247) sobre o acolhimento precoce de crianças em instituições. Segundo as autoras:

os cuidadores, por sua vez, também manifestaram a demanda por um holding institucional, uma sustentação de seu trabalho, que promova condições de cuidados estáveis e que permita um envolvimento mais próximo e claro com as crianças. Além disso, verbalizaram a necessidade de maior amparo emocional para lidarem com os seus sentimentos e fantasias, acionados durante a interação com as crianças.

Este tema torna-se ainda mais importante quando compreendemos o impacto que as instituições têm em nossa identidade. Segundo Kaës (1989: 69-70, grifo do autor),

as organizações constituem uma parte da nossa personalidade (...) dessa maneira, pode-se considerar que a dissolução ou uma tentativa de mudança de uma organização pode produzir diretamente uma desagregação da personalidade; não por projeção mas em razão direta do fato de que o grupo e a organização são a personalidade dos seus membros (...) as instituições e as organizações são depositárias da sociabilidade sincrética ou da parte psicótica, e que isso explica bem a tendência para a burocracia e para a resistência à mudança.

Integrando as ideias de holding, do psicanalista inglês Donald Winnicott, e de Renè Kaës, psicanalista francês que estudou as instituições, acredito que mais do que um estabelecimento de saúde, o ASM é parte constitutiva da identidade de seus trabalhadores. Quando esta instituição (no sentido de movimento, de campos de forças) que os constitui ameaça ruir, o que se vivencia é o caos, que coloca em xeque a estrutura construída em cada indivíduo, através do tempo e das relações.

Nestas perspectivas téoricas, a maneira como cada trabalhador se defenderá desta desorganização dependerá, também, de suas estruturas subjetivas que contemplam não somente aspectos psíquicos da construção de sua identidade pessoal, mas também sua implicação com o espaço e com o trabalho no qual está inserido. 
Importante sinalizar que estou incluindo outras perspectivas teóricas (de orientação psicanalítica das escolas inglesa e francesa) por acreditar que a multirreferencialidade nos oferece possibilidades de ampliação do campo de análise. Lourau também se utilizou de multiplas referências, inclusive de fora do campo sociológico, para construir a Análise Institucional ao lado de Georges Lapassade e outros autores. Contudo, cabe enfatizar que Lourau também sinalizou que

boa parte do sistema de referência ou quadro teórico é potencializada, pois todo praticante de intervenção - não importa qual seja seu paradigma - sabe que nem as técnicas mais etnometodológicas de observação nem a atitude de escuta mais empática nem as representações que pouco a pouco fazemos da situação, levando-a a entrar no "molde" de nossos conceitos, são tão operatórias quanto o humilde material colhido na negociação permanente, e com freqüencia muito terra-a-terra, entre interventores e clientes (LOURAU, 2004: 218-9).

Realizada esta explicação, podemos voltar à análise do sentimento de confusão e da sensação de desintegração dos trabalhadores, como representada nesta fala:

Eu fico tão indeciso, me sinto tão esquizofrênico com essa questão (do ambulatório tornar-se CAPS), tão cindido, porque eu tenho tanta pressa e eu quero que demore tanto, ao mesmo tempo" (Diário de pesquisa - FP).

É possível supor que o receio do desconhecido está relacionado não somente ao que fazer quando o serviço tornar-se um CAPSij, mas a como as relações humanas, políticas, institucionais, sociais e culturais influenciarão estes novos fazeres:

Mas eu estou falando da precariedade da forma de compreensão da criança, que chega aqui, que a gente tem que conversar com professores, com diretores... eu acho difícil. 'O que eu faço agora, e se ele bater no outro? '(pergunta a diretora). Cada tipo de pergunta...que você fala: gente, como assim? O que eu estou falando? O que é isso? Que queixa é essa? (Diário de pesquisa $-\mathrm{FP})$.

\section{Alguns analisadores}

$\mathrm{O}$ analisador se configura por situações que colocam a realidade da instituição em análise. Segundo Rossi e Passos (2014: 175), "pode ser tomado tanto como o evento que denuncia, quanto aquele portador da potência da mudança”. O fato, segundo os autores, é que o analisador revela o conteúdo latente e, assim, promove certa desorganização, na medida em que também pretende ressignificar conteúdos conhecidos.

Assim, um dos analisadores desta pesquisa foi o tempo de espera que aparece, primeiramente, em minha entrada no campo.

Logo que o projeto de pesquisa foi aprovado pelo CEP, eu o submeti à Secretaria Municipal de Saúde - com quem eu havia realizado conversas anteriores para construir a 
metodologia de pesquisa. Contudo, foram aproximadamente três meses sem qualquer resposta do Secretário Municipal, apesar de minha insistência. Conforme registrei em diário de pesquisa, "na semana de sua aprovação eu precisei dizer à Secretaria que, ou eles me retornavam até o final daquela semana, ou eu mudaria o munícipio a ser pesquisado" (Diário de pesquisa - OP). Somente após meu posicionamento é que fui autorizada a entrar em campo.

Com este tempo de espera, questionei-me: de que forma a macrogestão está implicada com a promoção de cuidado dos usuários do SUS e dos trabalhadores desta pasta?

Esta questão se manteve como pano de fundo de toda a pesquisa e, analisando em retrospectiva, apareceu muito antes dela, ou seja, quando escolhi este município como campo de pesquisa.

Quando comecei a gestar meu projeto, minha intenção era comparar três municípios. Mas, quando entendi que o tempo do mestrado é efêmero, precisei fazer uma escolha e esta escolha se deu a partir de meu posicionamento enquanto cidadã. Residindo no município pesquisado há poucos meses, precisei realizar uma denúncia contra uma conduta médica de uma Unidade de Pronto-Atendimento (UPA). Esse evento se deu muito próximo ao fechamento do esboço de meu projeto; então, mobilizada pela conduta reprovável e, fundamentalmente, pelas inúmeras histórias de negligências médicas que chegaram até mim após esta denúncia, através de conhecidos, eu me perguntei: por que os médicos agem desta forma, nesta cidade? Qual o lugar da gestão nisso tudo? E qual o posicionamento da população diante da precariedade dos atendimentos?

Como descrito anteriormente, trata-se de um município de grande porte, com aproximadamente quatrocentos mil habitantes. $\mathrm{Na}$ época desta pesquisa, o cenário relacionado ao SUS estava configurado da seguinte forma: 15 Unidades Básicas de Saúde (UBS); 49 Estratégias de Saúde da Família (ESF); 8 Serviços de Referência da Atenção Básica (SRefAB); 4 Unidades de Pronto-Atendimento (UPA); Serviço de Atendimento Móvel de Urgência (SAMU); 1 Centro de Atenção Psicossocial (CAPS II); 4 Ambulatórios de Saúde Mental, sendo 1 para atendimento infanto-juvenil, 2 para atendimento de adultos e 1 para atendimento de adultos usuários de álcool e outras drogas; 1 Serviço Residencial Terapêutico; 1 Equipe de Consultório na Rua (eCR) e 1 oficina de geração de renda. O município não possui Hospital Geral de gestão municipal, contando com leitos em estabelecimentos privados (que não contemplam internação às crises psíquicas que, neste caso, são reguladas pela Central de 
Regulação de Oferta de Serviços de Saúde - CROSS - e encaminhadas para municípios do entorno quando há vagas).

Um ponto interessante que também nos revela o desinvestimento histórico na Política de Saúde, especialmente na Política de Saúde Mental na Atenção Básica, se refere aos SrefAB (o nome foi alterado para preservar o sigilo em relação ao município pesquisado). Estes são serviços com especialidades médicas e odontológicas que foram projetados para atuar enquanto Núcleos de Apoio à Saúde da Família (NASF). Além de não cumprirem com o objetivo inicial (não há equipes de NASF no município), estas unidades recebem encaminhamentos das equipes das ESF, ao mesmo tempo que são responsáveis por determinadas áreas de abrangência territorial.

Ao longo da pesquisa, o que mais escutei sobre estes serviços foi a dificuldade de se inserirem na rede de cuidados, pois operam na lógica de forma mais ambulatorial do que os próprios ambulatórios - sendo que estes últimos fazem um grande esforço para atender a Política de Saúde Mental.

Outro ponto importante sobre o posicionamento da macrogestação no que se refere à Política de Saúde Mental é o próprio reordenamento do ASM. O processo de transição para CAPSij ocorreu mobilizado por um agente externo - o Ministério Público - através de Termo de Ajustamento de Conduta (TAC). Este TAC determinava, além do cadastramento do CAPSij, a implantação de mais 4 Serviços Residenciais Terapêuticos (SRT), a reorganização do CAPS II para CAPS III, o cadastramento do Ambulatório de Álcool e outras Drogas como CAPSad III, o cadastramento dos Ambulatórios de Saúde Mental Adulto (são dois) como CAPS II, 1 Unidade de Atenção Residencial de caráter transitório para adultos e 1 Unidade de Atenção Residencial de caráter transitório para crianças e/ou adolescentes, e o Consultório na Rua (este estava sendo implantado na época da pesquisa).

Até a finalização deste artigo, não foram encontradas informações oficiais sobre o cumprimento deste TAC. No sistema DATASUS, vinculado ao Ministério da Saúde, até o mês de maio de 2020 constava a inscrição de somente dois Centros de Atenção Psicossocial no município.

Feito este recorte, que considero importante, acerca do contexto sócio-histórico do município, centremo-nos no analisador 'tempo de espera' que, também, aparece na oferta de cuidado: "tomei ciência de que a fila de espera para inserção no tratamento é de um ano, aproximadamente” (Diário de pesquisa - OP). 
Esta observação, registrada em diário de pesquisa, diz respeito à inserção de crianças e adolescentes em dispositivos de cuidado do ASM infanto-juvenil. Apesar de a triagem (termo utilizado pelos trabalhadores para se referir ao primeiro atendimento) acontecer com mais agilidade e sem demanda reprimida, a entrada efetiva ao tratamento poderia demorar até um ano.

Por conta desta realidade, a equipe procurou se reorganizar em grupos de acolhimento, divididos por faixa etária. A partir da intervenção socioanalítica, estes grupos passaram a incluir um profissional de cada miniequipe (outro dispositivo que será abordado adiante). Deste modo, todos os territórios eram contemplados e as reflexões para a construção do Projeto Terapêutico Singular (PTS) dos usuários fluiriam de forma mais dialógica e integrada.

Porém, este analisador também aparece neste novo modelo de atendimento:

a gente faz grupo de acolhimento, aí tem uma lista de espera para grupo de acolhimento (...) depois de 6 meses a gente fala assim 'ah, agora faz bastante tempo, vamos avaliar de novo, vamos chamar de novo' e assim a gente vai... a gente não consegue sair desse ciclo" (Diário de pesquisa - FP).

Compreendo que o analisador 'tempo de espera' denuncia a incoerência do sistema, ao ofertar acesso, mas não ofertar integralidade e equidade no cuidado. Todos os usuários encaminhados ou que acessaram o serviço por demanda espontânea recebem o primeiro atendimento, chamado de triagem; contudo, isto não garante a inserção no tratamento. Até mesmo o dispositivo criado pelos trabalhadores para promover acolhimento dos novos usuários (grupo de acolhimento) foi laçado por este sintoma institucional, que é a espera. Para minimizar a angústia criada pelo fato de não conseguirem incluir novos usuários no serviço, os trabalhadores apostavam na chegada de uma nova profissional de psicologia.

Assim, outro analisador se revela e está à expectativa. Através das falas dos trabalhadores podemos pensar que a rede e a macrogestão também criam expectativas de que os profissionais do Ambulatório resolverão as demandas apresentadas: "a escola encaminha muito. A ESF encaminha muito... casos que a gente está vendo que não são para cá” (Diário de pesquisa - FP). Os trabalhadores acrescentam:

Eu penso que a maior dificuldade é a psicologização de tudo, e a patologização de tudo. Às vezes, em um primeiro momento, a pessoa até entende que não é aqui, mas ela não consegue generalizar para outros casos (...) a fala dela é assim: 'mandei os quatro irmãos desta mesma família porque é problema de comportamento e vulnerabilidade social' (Diário de pesquisa FP). 
A expectativa que os serviços da rede intersetorial projetam neste ASM também é motivo de angústia por parte dos trabalhadores, especialmente neste momento de transição, pois, uma vez que estão sendo convocados a atuar como CAPSij e, portanto, a atender os casos graves e severos, eles não têm para onde referenciar os casos de complexidades leve e moderada - porque não há Política de Saúde Mental na Atenção Básica -, fazendo com que a demanda seja maior do que a capacidade de absorção do serviço.

Esta expectativa também vem descrita na visão dos trabalhadores sobre a macrogestão: existe uma postura assim, 'vamos abraçar tudo, não vamos deixar voltar nada', e isso está sendo bem ruim (...) a gente não consegue avançar, e não vamos conseguir porque todo mundo aqui tem limite, e aí, o que a gente faz? Faz grupo de acolhimento, aí tem fila de espera para o grupo de acolhimento (Diário de pesquisa - FP).

A macrogestão espera que este serviço possa acolher as demandas que emergem a fim de cumprir com o que determina a legislação; porém, há uma questão sem resolução que todos também esperam que seja problematizada e resolvida: se o ASM está sendo convocado a ofertar atendimento na lógica do CAPSij, para onde referenciarão os casos que chegam e que não compõem a complexidade deste serviço, mas que também necessitam de acompanhamento em saúde mental?

Não há outro equipamento de saúde vinculado ao SUS que oferte tal atendimento, apenas este ASM. Então, a pergunta é: o que se espera que a equipe faça?

Outro analisador está no fato de que "a equipe não contabiliza os profissionais médicos como sendo parte dela” (Diário de pesquisa - OP).

Resgatando brevemente, após algumas tentativas infrutíferas de realizar entrevista semiestruturada, os médicos trabalhadores deste ASM participaram desta pesquisa ao tomarem contato com o formulário eletrônico que foi impresso e entregue em mãos pelo coordenador local. As perguntas contidas neste questionário versavam sobre a compreensão dos profissionais a respeito das diretrizes do SUS, da participação nas reuniões de equipe técnica e sobre Apoio Matricial. Os dois médicos afirmaram ter formação em Saúde Coletiva/Pública, mas não se aprofundaram na resposta sobre o porquê de não participarem da reunião de equipe técnica - um apenas sinalizou a incompatibilidade de horários. Quando questionados em quais momentos discutem casos com a equipe, ambos descreveram que esta comunicação acontece durante o atendimento médico. Esta resposta nos leva a questionar: qual o tipo de discussão que se estabelece? Considerando que a demanda de atendimento é grande, e que para uma compreensão profunda do contexto e dos aspectos que constituem os sujeitos são necessários 
tempo e espaço dignos de reflexão, podemos inferir que há grande probabilidade destas discussões centralizarem-se em ações ambulatoriais, para não dizer medicamentosas, ferindo o princípio da integralidade do cuidado.

Quanto à realização de Apoio Matricial, um deles respondeu que está em desenvolvimento, enquanto o outro respondeu que realiza matriciamento via telefone, quando solicitado. Cabe explicar que o telefone pode ser um meio para produzir demanda (assim como as demais ferramentas tecnológicas poderão atuar neste sentido), mas não substitui o encontro físico nem se configura enquanto Apoio Matricial no sentido em que este foi desenhado e que vem sendo vivenciado em diversos municípios. O contato telefônico pode e deve ser um uma forma de aproximação entre os serviços, um instrumento para elucidação de dúvidas, um caminho para a construção coletiva do cuidado, porém não se configura enquanto arranjo organizacional.

Portanto, como construir uma ação de CAPSij quando os profissionais médicos vivenciam uma força instituída que os impede de rever suas práticas? Esta é outra questão que a pesquisa levantou e que, mais uma vez, aponta para a contradição descrita anteriormente sobre a convocação da macrogestão para uma atuação desta equipe a este modelo de atenção e, também, para a sobreimplicação de muitos trabalhadores, que não tecem uma crítica voltada a estas relações institucionais.

\section{Análise de implicações dos trabalhadores}

A implicação, como explica Monceau (2008: 21) é “a relação que indivíduos desenvolvem com a instituição" e, uma vez que todos nós desenvolvemos relações com as instituições, não temos como fugir da implicação. Portanto, não se trata de analisar se o sujeito está ou não implicado. Ele está! A questão é analisar como. É uma “análise do sistema de lugares, do assinalamento do lugar que ocupa, que busca ocupar e do que lhe é designado a ocupar, com os riscos que isto implica" (BARROS, 2007: 231 citado por PEZZATO E PRADO, 2013: 172-3). A implicação nos mostra que não existe neutralidade; portanto, sua análise envolve uma leitura ampliada sobre as relações que se estabelecem, quer seja entre os profissionais, entre estes e a pesquisadora e entre todos e as instituições que nos inscrevem. É necessário compreender que a implicação não é um processo consciente (como um engajamento); ela acontece queiramos ou não, porque implicação é relação. E, além de implicados, podemos nos encontrar sobreimplicados. 
A implicação é um nó de relações; não é "boa" (uso voluntarista) nem "má" (uso jurídicopolicialesco). A sobreimplicação, por sua vez, é a ideologia normativa do sobretrabalho, gestora da necessidade do "implicar-se'. (...) A implicação (...) deve ser analisada individual e coletivamente, o que supõe atividade intensa e, muitas vezes, penosa. Apesar de nada haver nela de essencialmente passivo, uma dificuldade quanto a sua análise, conforme assinala Guigou, é que a implicação se encontra camuflada pela sobreimplicação, mantida à sombra da última (LOURAU, 2004: 190-1).

A sobreimplicação nos impossibilita o distanciamento necessário para que a análise sobre nós aconteça. Podemos observá-la nos seguintes pronunciamentos: "Não consigo enxergar a potência que você procura"; "Estamos no olho do furacão!” (Diário de pesquisa FP).

Como enxergar potência se, para isso, é preciso tomar distância e analisar o trabalho desenvolvido por outro prisma? Como tomar distância estando imersos no olho do furacão, sem saber a que horas essa imensa tempestade chegará? O grande problema do olho do furacão é que ele mobiliza uma falsa sensação de calmaria e o perigo está justamente nesta condição: por deixar o ambiente aparentemente calmo, por vezes as pessoas abandonam seus abrigos, baixam suas guardas e se colocam em risco, uma vez que a qualquer momento o furacão poderá chegar.

Podemos utilizar esta metáfora para compreender que o anúncio do furacão chegou até a equipe através da notícia sobre o reordenamento do serviço. Neste momento houve muita mobilização interna (dos conteúdos subjetivos dos trabalhadores) e externa (questões de ordem prática e relacionadas aos processos de trabalho). Estas mobilizações provocaram angústia e desorganização. Instalou-se o caos à espera do desconhecido. Esta espera é exatamente a zona nomeada como olho do furacão: aquele tempo-espaço no qual se sabe que a tempestade chegará, mas não se sabe quando.

Neste sentido, há momentos em que a equipe se coloca em estado de alerta, apresentando conteúdos persecutórios, inclusive relacionados à minha presença, e outros em que se coloca em estado de inércia. Ambos impossibilitam o processo criativo e os impede de identificar suas potências, já que tendem a concentrar suas energias na construção de suas defesas e, em certos momentos, na manutenção do que está instituído.

A reestruturação do serviço é um objeto temido e, ao lado desta macropolítica instável e de relações micropolíticas que precisam ser acolhidas e analisadas, os trabalhadores são empurrados cada vez mais para dentro do olho do furacão. 
Quando trabalhamos coletivamente a análise deste momento, especialmente no último encontro dedicado à restituição, observamos que a instituição que se propõe a cuidar do sofrimento também adoece:

Só que eu acho que a gente está tentando arrumar uma saída para uma coisa que a gente não pode se cobrar ao ponto, assim, porque o profissional fica mal também. Se ele manda (contrarrefenciar para Unidade Básica de Saúde), ele pensa: 'ai que dúvida, eu precisava ver mais'. Então é uma faca de dois gumes esse serviço (Diário de pesquisa - FP).

Esta é apenas uma fala dentre tantas compartilhadas que representam a imersão no olho do furacão.

Ontem eu estava numa reunião que tinham 3 pessoas da Atenção Básica. A fala que eu escutei é assim: 'mas os médicos têm medo. E se a pessoa se mata na frente dele, a mãe processa, ele se prejudica, fica agressivo e bate no outro'. Pode até ser desculpa, pode até ser pretexto para encaminhar (ao ASM), não vou julgar isso, mas olha o quanto que nós estamos discutindo da nossa segurança. Nós passamos 50 minutos em acolhimento e ainda temos dúvida. Fala um médico, para mim, da Atenção Básica, que atende em 10 minutos, para ter segurança para falar que não é lá, e que é aqui? Então, na dúvida, vem para cá (Diário de pesquisa - FP).

O sofrimento produz inércia no trabalho e alimenta o que está instituído, por se configurar uma zona de proteção em defesa do desconhecido. Esta inércia impossibilita a criação de saídas: “algumas pessoas não se atualizam e desenvolvem uma clínica que não se conecta aos princípios do SUS”, compartilha um dos trabalhadores em reunião de equipe técnica.

A clínica privada, para dentro de instituições públicas, infelizmente, não é incomum. Muitos profissionais se defendem das vulnerabilidades que se apresentam nestes serviços mantendo-se distantes de uma clínica ampliada, operando de forma reducionista e, muitas vezes, revestida da fantasia de que esta é a forma correta de se fazer, principalmente nos campos da psicologia e da medicina.

Outro ponto é que esta fala denuncia as relações contraditórias entre os pares. Há muitas afetações entre os membros da equipe, mas pouco (ou quase nada) transparece a esse respeito. As críticas não são dirigidas a ninguém especificamente. Elas são postas ‘ao vento’ e, com isso, impossibilitam o tratamento adequado.

Para o enfrentamento da inércia e para o tratamento da angústia, uma de minhas ofertas de intervenção foi o mapeamento da rede intersetorial, para otimizar os fluxos de diálogos entre as políticas municipais e, também, para compartilhar a responsabilidade pelo cuidado dos usuários com foco no princípio da integralidade. Porém, a resposta que recebi dos trabalhadores é que eles aguardavam um mapa que a Secretaria Municipal de Saúde elaboraria. 
Há um movimento coletivo de dar conta de toda a demanda, provocado pela pressão da macrogestão e pelo perfil dos trabalhadores. Muitos assumem o lugar materno de cuidado, de forma inconsciente, mobilizando-se demasiadamente com o sofrimento infantil. Com isso, são impedidos de construir novas estratégias que convoquem a participação de outros atores, inclusive da própria equipe.

Contudo, apesar de momentos inertes, a vida acontece no serviço. Foi possível perceber inúmeros movimentos instituintes, de criação em busca de soluções para organizar os processos de cuidado, apesar da disparidade em relação ao tamanho da equipe e da extensão territorial: “de dezembro para cá mudou e desmudou muitas coisas" (Diário de pesquisa - FP).

É inegável que um único serviço não dará conta dos cuidados da infância e juventude, mas a potência de movimento fez com que esta pequena equipe se dividisse em três miniequipes e começasse a atuar a partir da lógica territorial.

Sem pretender ser redundante, as pequenas miniequipes (ou, melhor dizendo, microequipes) se responsabilizam pelos atendimentos, pelos acolhimentos, pelos matriciamentos e pela construção de rede intersetorial. Embora muitas vezes imersos em desorganização e sentimento de incapacidade, é possível identificar movimento de vida que, através da potência criativa, possibilita a invenção de atos promotores de integralidade no cuidado.

Todas as miniequipes têm feito o movimento de sair, de matriciar, não tem uma coisa assim: equipe azul vai tal dia, a amarela... não está sistematizado. Vai onde tem um caso, ou onde chamam, esse é o caminho no momento, mas estamos começando as nos organizar para ir, inclusive, onde não somos chamados. A gente optou por começar por onde tem um caso para discutir, um PSF que chamou ou uma escola que chamou, mas a gente quer se organizar para estar em todos os lugares, mesmo onde não fomos chamados (Diário de pesquisa - FP).

A gente está indo mais dentro da demanda, mas com planejamento para ir em escola que a gente que ir, mas não deu pra ir, porque é pesado, não dá. E... a gente está nesse movimento de caminhar mais, mas a gente está caminhando (Diário de pesquisa - FP).

Cada miniequipe conta com poucos representantes: um grupo tem dois profissionais, enquanto os outros dois grupos possuem três profissionais. Importante ressaltar que o ponto fundamental das equipes de referência (miniequipes) é considerar o sujeito como responsabilidade do coletivo, ou seja, não é deste ou daquele profissional. O compartilhamento dos casos clínicos acontece de forma corresponsável, desconstruindo a lógica ambulatorial e verticalizada, possibilitando discussões a partir de múltiplos olhares, inclusive o olhar do 
próprio usuário (e de seus familiares, quando for o caso), que também é corresponsável pelo seu cuidado.

As miniequipes trocavam entre si experiências criadas para dar conta dos fluxos de trabalho. Por exemplo, uma delas resgatou todos os casos clínicos em demanda reprimida e descreveu a queixa, o tempo de espera e a ESF à qual pertenciam. Com isto, tiveram dimensão das demandas que são encaminhadas e quais Unidades de Saúde produziam mais encaminhamentos, promovendo a otimização dos processos de Apoio Matricial a partir deste diagnóstico territorial.

O reconhecimento da importância do Apoio Matricial aparece em falas como esta:

mas quando a gente vai também, a gente gosta de ver... a experiência que a gente tem tido é que a ESF está fazendo muita coisa; a gente foi numa ESF e a enfermeira falou 'muitos vêm aqui, eu acabo nem encaminhando, eu chamo, eu converso; a gente abrangeu um monte de situações, um monte de casos, tem sido assim, a gente acaba falando de várias situações, tem sido bem dinâmico (Diário de pesquisa - FP).

O Apoio Matricial é um processo de trabalho de encontros, de produção de subjetividade e, por sê-lo, seus desafios são permanentes. É um processo tecido com muitas mãos e muitas vozes, em tempos e ritmos distintos para cada sujeito e para cada encontro. Ele demanda extrema delicadeza e sensibilidade porque aproxima serviços e sujeitos com objetivos e fazeres diferentes, com propostas que podem se desencontrar. Muitas vezes seus resultados vêm em conta gotas, a partir de cada caso clínico ensinante, mas, quando produz efeito de encontro, o aprendizado e a transformação são duradouros:

intensificou e depois da miniequipe organizou melhor; agora eu vejo bastante caso de moderado para grave (...) Não sei se tem a ver com o matriciamento... pode ser que tenha (Diário de pesquisa - FP).

\section{Análise de implicação da pesquisadora}

A Socioanálise, enquanto referencial teórico-metodológico, subverte a lógica das pesquisas positivistas na qual o pesquisador é o saber presente na relação com o pesquisado. A construção de conceitos como implicação e sobreimplicação nos aponta que a suposta neutralidade da pesquisa é ilusória e nos serve, no meu ponto de vista, como subterfúgio de defesa contra as nossas identificações e angústias. O fato é que não estamos neutros e, por isso, analisar a implicação do pesquisador é fundamental para a construção do campo de pesquisa.

Nas palavras de Lourau (1994: 92, grifo do autor): 
Se realmente compreendermos que a análise da implicação do pesquisador deva estar no âmago da pesquisa, talvez isso possa levar à produção de um novo tipo de intelectual, ao qual a pergunta se referia. Penso ser isso o que podem fazer os intelectuais: interessar-se apaixonadamente pela contradição, ao invés de "levar ao povo" a verdade universal.

Analisando a minha implicação no percurso da pesquisa, compreendo que os papeis de pesquisadora e trabalhadora se fundiram em um duplo mandato: de quem vem de fora estudar, mas também de quem vem agregar, contribuir e compartilhar experiências que possam objetivamente provocar mudanças na maneira de operar a instituição: "neste momento percebi que minha presença ali iria muito além de uma coleta de dados” (Diário de pesquisa - OP).

Minha identificação com o fazer na Política de Saúde Mental infanto-juvenil promoveu em mim diversos tipos de implicação e, por vezes, sobreimplicações, porque me senti, assim como eles fazem com os casos clínicos, convocada a dar conta do sofrimento e ofertar soluções. Em muitos momentos recuei e analisei minhas práticas. Outras análises só foram possíveis após a conclusão da pesquisa.

A questão é que na dinâmica coletiva e inconsciente reproduzimos atos: a equipe é convocada a dar respostas, a equipe me convoca a dar respostas; a equipe se movimenta no sentido de abraçar as demandas que surgem, eu me movimentei no sentido de dar conta das demandas que dela surgiam. Essa fluidez das relações é o que compõe o cotidiano dos serviços e da pesquisa-intervenção. Este outro (que eles representam, que eu represento para eles, que os autores estudados nos representam) tem o poder de nos mobilizar, de nos retirar de nossos confortáveis lugares e nos provocar não somente angústia, mas questões que são capazes de abrir novos horizontes: “compartilhamos algumas experiências profissionais, pensamentos e reflexões sobre a clínica da infância e adolescência” (Diário de pesquisa - OP).

No momento em que os corpos se encontram e produzem afetos, permito-me compartilhar vivências. Estabelecemos diálogos a partir da demanda do serviço, ou de determinado momento/situação, ou entre um encontro despretensioso e outro tomando café, tecendo conexões que nem sempre são simples. Às vezes, estes encontros promovem persecutoriedade e descrença também em mim. Outras, no entanto, provocam risos, saídas, reflexões e aprofundamentos.

A questão é que analisar a nossa implicação enquanto pesquisadores é uma tarefa especialmente delicada e, ao mesmo tempo, transformadora. O lugar que me ofereceram foi de quem soluciona o problema, mas, no plano velado de cada convocação, estava o pedido por acolhimento. Nestas narrativas vivas, a imagem ao fundo sempre foi esta: acolher. Por vezes, 
este ato se transvestia de holding institucional, de contenção da angústia; outras, acolher significava ouvir sem produzir questões; outras, era receber e provocar reflexões; ou, ainda, compartilhar experiências, enriquecer nossos repertórios e colorir nossas histórias.

Neste movimento de vida institucional, avancei e recuei no meu sentimento e na análise do destino de minhas afetações. A imersão no campo de pesquisa, a partir da Socioanálise, não é somente uma convocação a um trabalho sobre o outro, mas, especialmente, a um trabalho sobre nós mesmos e sobre a nossa implicação nos enfrentamentos das injustiças sociais. É sobre resistir diariamente à sedução da alienação. É empreender esforços, sempre coletivos, contra os desmontes perversos e recorrentemente vividos, principalmente nos últimos anos, nas Políticas Sociais. É um referencial teórico-metodológico que questiona o que nos institui enquanto pesquisadores quando estamos imersos em nosso próprio olho do furacão.

\section{Considerações finais}

A Política de Saúde Mental Infanto-Juvenil ainda caminha a passos lentos quando comparada à implantação dos serviços substitutivos destinados ao público adulto. Aos poucos, essa realidade tem sido transformada com a intervenção do Ministério Público. Este órgão, a partir dos Termos de Ajustamento de Conduta (TAC), tem convocado os gestores municipais para o cumprimento de políticas públicas historicamente negligenciadas. Em consequência desta intervenção, a macrogestão do município pesquisado tem buscado reorganizar seu modelo de atendimento em saúde mental. Uma destas reorganizações é o cadastramento do Ambulatório de Saúde Mental Infanto-Juvenil para a modalidade de CAPSij.

Tomar ciência deste reordenamento constituiu-se em uma notícia intrinsecamente mobilizadora de afetos, porque anunciou que o desconhecido se aproximava, convocando os sujeitos a desocuparem seus lugares.

O contato com este novo, de forma confusa e atravessada, imergiu os trabalhadores no 'olho do furacão' - uma zona perigosa que faz com que estes estejam em constante vigilância, desenvolvendo, em diversos momentos, defesas reativas na tentativa de preservar o instituído que os protege do caos anunciado.

Neste contexto de contradições, angústias e reinvenções, a Socioanálise constituiu-se como um referencial teórico-metodológico potente, ao intervir na dinâmica do serviço e na dinâmica das relações. Cabe destacar que sua função não é ofertar respostas prontas, mas possibilitar que, através da intervenção em ato, outros caminhos possam ser gestados. Podemos 
afirmar que, neste caso, a pesquisa se fez ainda mais efetiva porque nasceu da demanda dos próprios trabalhadores.

Mas, apesar de termos tecido encontros potentes, há um limite para estes trabalhadores que deve ser assumido pela Secretaria Municipal de Saúde. Considerando este apontamento, algumas ações foram problematizadas no encontro de restituição. Estas reflexões reiteram o que esta pesquisa demonstrou: é imprescindível o comprometimento de todos os sujeitos, de todas as instâncias, nos processos de cuidado que envolvem tanto as necessidades de saúde dos usuários quanto as necessidades dos trabalhadores do serviço.

Quanto à implicação dos profissionais, a pesquisa apontou que há momentos nos quais os encontros são produtivos e as reinvenções se dirigem a favor do usuário, promovendo atendimentos dignos e respeitosos conectados aos princípios do SUS. Em contrapartida, outros momentos são tomados pela sobreimplicação, em que a manutenção dos modelos instituídos atua em defesa contra a ruptura, impossibilitando a escuta entre os sujeitos.

Imergir neste campo de pesquisa me mostrou que, apesar do momento intempestivo e da solidão, os trabalhadores desvelam suas potências nos microprocessos cotidianos, como: na constituição das miniequipes; na criação do grupo de acolhimento, como possibilidade de superação do modelo centrado na queixa-conduta; nas intervenções realizadas na (e com a) rede intersetorial, especialmente com as Políticas de educação e de assistência social; no investimento, ainda que prematuro, em Apoio Matricial atentando-se às demandas das equipes da Atenção Básica; no olhar crítico sobre o modelo ambulatorial, compartilhado pela maioria dos trabalhadores deste serviço; na compreensão política do funcionamento do CAPSij, apropriando-se das legislações e materiais produzidos pelo Ministério da Saúde; na disponibilidade em acolher esta pesquisa, convocando-a a intervir nesta dinâmica compreendida por eles como modelo a ser superado; no investimento em capacitação profissional que fazem particularmente, muitas vezes sem apoio da Secretaria Municipal de Saúde.

Contudo, os desafios são constantes. Apesar do Ministério Público intervir, a partir dos Termos de Ajustamento de Conduta, vivenciamos recorrentes desmontes e retrocessos na Política de Saúde em âmbito nacional. Acontecimentos recentes revelam, cada vez mais, os interesses neoliberais e mercadológicos dos atuais gestores, em todos os níveis.

No que se refere ao recorte desta pesquisa, podemos citar dois deles, que impactam diretamente no fazer cotidiano dos trabalhadores da Política de Saúde Mental: a Nota Técnica 
$\mathrm{n}^{\mathrm{o}} 11 / 2019$ que, dentre outros retrocessos, reinclui os hospitais psiquiátricos no circuito dos atendimentos (BRASIL, 2019) e, mais recentemente, a Nota Técnica $n^{\circ} 03 / 2020$, que decreta o fim da implantação dos NASFs (BRASIL, 2020).

É preciso resistência e coletividade para enfrentarmos o rolo compressor de modelos de gestão que servem ao capital e que operam na lógica da segregação, da exclusão e da manutenção das disparidades sociais. É preciso posicionamento e controle social. É preciso que referenciais teóricos-metodológicos, como a Socionálise, nos produzam indignação, questionamentos e análise profunda de nossas implicações com os usuários, com a política de saúde e com os representantes eleitos para governar este país.

Deste modo, para concluir, esta pesquisa me ensinou que quando entramos em contato com a história do SUS passamos a compreender esse complexo sistema que tem a ousada missão de buscar garantir acesso à saúde para milhões de pessoas que vivem em um país desigual. Mas o SUS, embora considerado por muitos como parte de uma máquina estatal - por vezes movida a interesses privados e escusos - não se define assim.

Sem desconsiderar o caráter técnico, político, econômico, administrativo que o compõe, arrisco-me a afirmar que o SUS é maior do que isso. A força motriz do SUS somos nós: sujeitosusuários, sujeitos-trabalhadores, sujeitos-gestores, sujeitos-pesquisadores, sujeitoslegisladores, sujeitos-executores, sujeitos que embora imersos em um cenário de infinitas contradições, permanecem na luta em cada lugar deste país.

É nesse cotidiano, é nesse imenso fazer, nas relações um-a-um, sujeito-sujeito, que o SUS vai encontrando o combustível que o faz resistir e florescer, como um mandacaru, em meio a tantas adversidades. E é por estas, e por tantas outras, que vamos seguir na luta por seu ideário de justiça e igualdade.

\section{Referências}

BRASIL. Relatório Final da III Conferência Nacional de Saúde Mental. Brasília/DF: Ministério da Saúde; 2002(a). Disponível em http://conselho.saude.gov.br/biblioteca/Relatorios/saude_mental.pdf. Acesso em 22 set. 2017.

Ministério da Saúde. Portaria GM no 336 de 19 de fevereiro de 2002 (b). Estabelece que os Centros de Atenção Psicossocial poderão constituir-se nas seguintes modalidades de serviços: CAPS I, CAPS II e CAPS III, definidos por ordem crescente de porte/complexidade e abrangência populacional, conforme disposto nesta Portaria. Disponível

em 
http://bvsms.saude.gov.br/bvs/saudelegis/gm/2002/prt0336_19_02_2002.html. Acesso em 29 dez. 2019

. Portaria no 3.088 de 23 de dezembro de 2011. Institui a Rede de Atenção Psicossocial para pessoas com sofrimento ou transtorno mental e com necessidades decorrentes do uso de crack, álcool e outras drogas, no âmbito do Sistema Único de Saúde (SUS). Disponível http://bvsms.saude.gov.br/bvs/saudelegis/gm/2011/prt3088_23_12_2011_rep.html. Acesso em 22 set. 2017

CAMPOS, Gastão Wagner de Sousa; DOMITTI, Ana Carla. Apoio matricial e equipe de referência: uma metodologia para gestão do trabalho interdisciplinar em saúde. Cad. Saúde Pública, Rio de Janeiro, v. 23, n. 2, p. 399-407, Fev. 2007 . Disponível em $<$ http://www.scielo.br/scielo.php?script=sci_arttext\&pid=S0102-

311X2007000200016\&lng=en\&nrm=iso>.

COUTO, Maria Cristina Ventura; DELGADO, Pedro Gabriel Godinho. Crianças e adolescentes na agenda política da saúde mental brasileira: inclusão tardia, desafios atuais. Psicol. clin., Rio de Janeiro, v. 27, n. 1, p. 17-40, Jul 2015 . Disponível em <http://www.scielo.br/scielo.php?script=sci_arttext\&pid=S0103-

56652015000100017\&lng=en\&nrm=iso>. Acesso em 29 Dez. 2019.

GOLIN, Gabriela; BENETTI, Silvia Pereira da Cruz. Acolhimento precoce e o vínculo na institucionalização. Psic.: Teor. e Pesq., Brasília , v. 29, n. 3, p. 241-248, Set. 2013. Disponível em <http://www.scielo.br/scielo.php?script=sci_arttext\&pid=S010237722013000300001\&lng=en\&nrm=iso>. Acesso em 30 jun. 2020.

KAËS, René. Realidade Psíquica e Sofrimento nas Instituições. In: Kaës, René et al. A instituição e as instituições: estudos psicanalíticos. Trad. Joaquim Pereira Neto. São Paulo: Casa do Psicólogo; 1989.

L'ABBATE, Solange. O analisador dinheiro em um trabalho de grupo realizado num hospital universitário em Campinas, São Paulo: revelando e desvelando as contradições institucionais. In: Rodrigues HBC e Altoé S. SaúdeLoucura (8). Análise Institucional.São Paulo: Hucitec; 2004.

LOURAU, René. René Lourau na UERJ: Análise Institucional e Práticas de Pesquisa. Rio de Janeiro: Universidade do Estado do Rio de Janeiro; 1993.

. Analista institucional em tempo integral. Altoé, Sonia (orgs). São Paulo: Hucitec, 2004.

MONCEAU, Gilles. Implicação, sobreimplicação e implicação profissional. Fractal, Rev. Psicol., Rio de Janeiro , v. 20, n. 1, p. 19-26, Jun 2008 . Disponível em $<$ http://www.scielo.br/scielo.php?script=sci_arttext\&pid=S198402922008000100007\&lng=en\&nrm=iso>. Acesso em 29 Jun 2020.

PEZZATO, Luciane Maria; PRADO, Guilherme do Val Toledo. Pesquisa-ação e pesquisaintervenção: aproximações, distanciamentos, conjugações. In: L'Abbate $S$ (org). Análise Institucional e saúde coletiva no Brasil. São Paulo: Hucitec; 2013.

ROSSI, André; PASSOS, Eduardo. Análise institucional: revisão conceitual e nuances da pesquisa-intervenção no Brasil. Rev. Epos, Rio de Janeiro , v. 5, n. 1, p. 156181, jun. 2014. Disponível em 
<http://pepsic.bvsalud.org/scielo.php?script=sci_arttext\&pid=S2178-

700X2014000100009\&lng=pt\&nrm=iso>. Acesso em 29 dez. 2019.

RIBEIRO, Paulo Rennes Marçal. História da saúde mental infantil: a criança brasileira da Colônia à República Velha. Psicol. estud., Maringá, v. 11, n. 1, p. 29-38, Abr. 2006. Disponível em <http://www.scielo.br/scielo.php?script=sci_arttext\&pid=S1413$73722006000100004 \& \operatorname{lng}=e n \& n r m=i s o>$. Acesso em 30 jun. 2020.

SCHECHTMAN, Alfredo. Textos da I Reunião Temática. In: Brasil. Caminhos para uma política de saúde mental infanto-juvenil. 2. ed. Brasília: Editora do Ministério da Saúde; 2005.

SEVERO, Ana Kalliny de Sousa; L'ABBATE, Solange; CAMPOS, Rosana Teresa Onocko. A supervisão clínico-institucional como dispositivo de mudanças na gestão do trabalho em saúde mental. Interface (Botucatu), Botucatu, v. 18, n. 50, p. 545556, Set. 2014. Disponível em <http://www.scielo.br/scielo.php?script=sci_arttext\&pid=S141432832014000300545\&lng=en\&nrm=iso>. Acesso em 29 dez. 2019.

SPINOZA, Baruch (1632-1677). Ética: Espinosa. Trad. Grupo de Estudos Espinosanos. Coord. Marilena Chauí. São Paulo: Editora da Universidade de São Paulo; 2015.

Cláudia Capelini Picirilli Mestra em Saúde Coletiva pela Faculdade de Ciências Médicas/ Universidade Estadual de Campinas (FCM/Unicamp) Obs: atualmente vinculada à FCM como aluna especial. Na época da pesquisa, vinculada ao Mestrado Profissional em Saúde Coletiva: Políticas e Gestão em Saúde E-mail: cpicirilli@gmail.com

Daniele Pompei Sacardo: Docente do Departamento de Saúde Coletiva, Faculdade de Ciências Médicas/UNICAMP E-mail: danielesacardo@gmail.com

\footnotetext{
${ }^{1}$ Dissertação original homônima, disponível em http://repositorio.unicamp.br/jspui/handle/REPOSIP/331947
} 